\title{
Time to PSA rise differentiates the PSA bounce after HDR and LDR brachytherapy of prostate cancer
}

\author{
Wojciech Burchardt, MD, PhD!, Janusz Skowronek, MD, Prof.',2 \\ 'Brachytherapy Department, Greater Poland Cancer Centre, ${ }^{2}$ Electroradiology Department, Poznan University of Medical Sciences, Poznan, \\ Poland
}

\begin{abstract}
Purpose: To investigate the differences in prostate-specific antigen (PSA) bounce (PB) after high-dose-rate (HDR-BT) or low-dose-rate (LDR-BT) brachytherapy alone in prostate cancer patients.

Materials and methods: Ninety-four patients with localized prostate cancer (T1-T2cN0), age ranged 50-81 years, were treated with brachytherapy alone between 2008 and 2010. Patients were diagnosed with adenocarcinoma, Gleason score $\leq 7$. The LDR-BT total dose was 144-145 Gy, in HDR-BT - 3 fractions of 10.5 or 15 Gy. The initial PSA level (iPSA) was assessed before treatment, then PSA was rated every 3 months over the first 2 years, and every 6 months during the next 3 years. Median follow-up was 3.0 years.

Results: Mean iPSA was $7.8 \mathrm{ng} / \mathrm{ml}$. In 58 cases, PSA decreased gradually without PB or biochemical failure (BF). In $24 \%$ of patients, PB was observed. In 23 cases (24\%), PB was observed using $0.2 \mathrm{ng} / \mathrm{ml}$ definition; in 10 cases (11\%), $\mathrm{BF}$ was diagnosed using nadir $+2 \mathrm{ng} / \mathrm{ml}$ definition. The HDR-BT and LDR-BT techniques were not associated with higher level of PB (26 vs. $22 \%, p=0.497)$. Time to the first PSA rise finished with PB was significantly shorter after HDR-BT then after LDR-BT (median, 10.5 vs. 18.0 months) during follow-up. Predictors for PB were observed only after HDR-BT. Androgen deprivation therapy (ADT) and higher Gleason score decreased the risk of $\mathrm{PB}(\mathrm{HR}=0.11$, $p=0.03 ; \mathrm{HR}=0.51, p=0.01$ ). The higher PSA nadir and longer time to PSA nadir increased the risk of PB (HR 3.46, $p=0.02 ;$ HR 1.04, $p=0.04$ ). There was no predictors for PB after LDR-BT.

Conclusions: HDR-BT and LDR-BT for low and intermediate risk prostate cancer had similar PB rate. The PB occurred earlier after HDR-BT than after LDR-BT. ADT and higher Gleason score decreased, and higher PSA nadir and longer time to PSA nadir increased the risk of PB after HDR-BT.

J Contemp Brachytherapy 2018; 10, 1: 1-9 DOI: https://doi.org/10.5114/jcb.2018.73786
\end{abstract}

Key words: bounce, brachytherapy, HDR, LDR, monotherapy, prostate cancer, PSA.

\section{Purpose}

Prostate brachytherapy (BT) is one of recommended treatment methods in early-stage prostate cancer $[1,2,3$, $4,5]$. Biochemical control is defined as a stable low prostate-specific antigen (PSA) level after BT. Biochemical failure (BF) after radiotherapy is defined as a PSA nadir value + $2 \mathrm{ng} / \mathrm{ml}$ (Phoenix) or as three consecutive increases in PSA (ASTRO) [6]. However, PSA levels may fluctuate during post-radiotherapy follow-up, without any clinical signs of cancer recurrence [7,8]. These benign PSA fluctuations are known as PSA bounces (PB), and are often observed after BT and/or external beam radiotherapy (EBRT). This phenomenon was first described in 1997 by Wallner [9]. Such variations are rarely observed after other treatment modalities, such as surgery, high intensity focused ultrasound, or cryotherapy [10]. The reported frequency of PB $>0,2 \mathrm{ml} / \mathrm{ng}$ after low-dose-rate brachytherapy (LDR-BT) varies between $30 \%$ and $40 \%$ over the first 2 years $[7,11$, 12,13,14]. A few studies have described PB after highdose-rate brachytherapy (HDR-BT) as monotherapy, and reported frequency of $\mathrm{PB}$ in such instances was over $>40 \%$ $[15,16]$. A high and long lasting PB could easily be misinterpreted as disease progression, potentially leading to the unnecessary therapy. Therefore, distinguishing PB from $\mathrm{BF}$ is crucial in follow-up of prostate cancer patients.

Time to PSA rise has been shown to be useful to differentiate between PB and BF after LDR-BT. Merrick et al. observed that $83 \%$ of the $\mathrm{PB}$ occurred in the first 30 months of follow-up [17]. Ciezki et al. have observed that BF occurred after a median of 22 months, whereas PB occurred after a median of 15.1 months $(p=0.013)$ [18]. Analogously, Crook et al. have reported PB at 15.2 months and BF at 30.9 months $(p=0.02)$ [7]. The study from France reported by Mazeron et al. confirmed the validity of this observations (17 vs. 27.8 months, $p<0.0001)$ [13]. 
Table 1. Patient characteristics

\begin{tabular}{|c|c|c|c|c|}
\hline Factor & $N$ & $N(\%)$ & $\begin{array}{l}\text { Average } \\
\pm S D\end{array}$ & Median \\
\hline Age [years] & 94 & 100 & $66 \pm 7.6$ & 66.0 \\
\hline \multicolumn{5}{|l|}{ BT } \\
\hline HDR-BT & 53 & 56 & - & - \\
\hline LDR-BT & 41 & 44 & - & - \\
\hline \multicolumn{5}{|l|}{ TNM } \\
\hline $\mathrm{T} 1 \mathrm{c}$ & 52 & 55 & - & - \\
\hline $\mathrm{T} 2 \mathrm{a}$ & 28 & 30 & - & - \\
\hline $\mathrm{T} 2 \mathrm{~b}$ & 4 & 4 & - & - \\
\hline $\mathrm{T} 2 \mathrm{C}$ & 9 & 10 & - & - \\
\hline n.d. & 1 & 1 & - & - \\
\hline \multicolumn{5}{|l|}{ Gleason score } \\
\hline$\leq 6$ & 77 & 82 & - & - \\
\hline 7 & 14 & 15 & - & - \\
\hline n.d. & $3^{\star}$ & 3 & - & - \\
\hline iPSA & 94 & 100 & $7.8 \pm 3.1$ & 7.3 \\
\hline \multicolumn{5}{|l|}{ Risk group } \\
\hline Low & 61 & 65 & - & - \\
\hline Intermediate & 33 & 35 & - & - \\
\hline \multicolumn{5}{|l|}{ ADT } \\
\hline Yes & 33 & 35 & - & - \\
\hline No & 61 & 65 & - & - \\
\hline $\begin{array}{l}\text { Prostate volume } \\
{\left[\mathrm{cm}^{3}\right]}\end{array}$ & 94 & 100 & $33.5 \pm 12$ & 35.0 \\
\hline PTV $\left[\mathrm{cm}^{3}\right]$ & 94 & 100 & $32.2 \pm 11$ & 31.0 \\
\hline $\mathrm{D}_{90}(\mathrm{BED})$ & 94 & 100 & $274 \pm 120$ & 243.0 \\
\hline $\begin{array}{l}\text { Follow-up } \\
\text { [years] }\end{array}$ & 94 & 100 & $3.0 \pm 0.7$ & 3.0 \\
\hline $\begin{array}{l}\text { Nadir PSA } \\
{[\mathrm{ng} / \mathrm{ml}]}\end{array}$ & 94 & 100 & $0.3 \pm 0.7$ & 0.1 \\
\hline $\begin{array}{l}\text { Time to nadir } \\
\text { [months] }\end{array}$ & 94 & 100 & $21 \pm 14$ & 21.0 \\
\hline \multicolumn{5}{|l|}{ PSA events } \\
\hline No PB & 58 & 62 & - & - \\
\hline PB & 23 & 24 & - & - \\
\hline $\mathrm{BF}$ & 10 & 11 & - & - \\
\hline$C F$ & 3 & 3 & - & - \\
\hline
\end{tabular}

$N$-number of patients, $B T$ - brachytherapy, HDR-BT-high-dose-rate brachyther apy, LDR-BT - low-dose-rate brachytherapy, TNM - tumor nodal staging UICC $7^{\text {th }}$ ed. 2010, IPSA - initial prostate antigen level, ADT - androgen deprivation therapy, Vol - volume, PTV - planning target volume, $D_{90}$ - dose in $90 \%$ of PTV, BED - biological effective dose, PB - PSA bounce, BF - biochemical failure, CF-clinical failure

* - patients were classified as low-risk group because of other factors
In our study, we reported differences between time of PSA rise before PB following HDR-BT and LDR-BT, both with and without androgen deprivation therapy (ADT). Other goal of this study was to identify the predictive factors of PB occurrence. The data can be implemented in daily practice to analyze patient's PSA changes. It can help to diagnose PB faster and with greater certainty after different BT modalities.

\section{Material and methods \\ Patient characteristics}

The analyzed group included 101 patients (aged 50-81 years) with clinically localized prostate cancer (T1-T2cN0), treated with BT alone from June 2008 to December 2010 in our hospital. All patients underwent BT with curative intent: LDR-BT (LDR-BT Group) or HDR-BT (HDR-BT Group). Three patients from the LDR-BT Group and four from the HDR-BT Group were not observed in our hospital and were excluded from the analysis. The median post-treatment follow-up lasted 3.0 years. All patients had biopsy proven adenocarcinoma with a Gleason score $\leq 7$, except 3 cases where Gleason scale data were unavailable (diagnosis made outside our hospital). The average iPSA value was $7.8 \mathrm{ng} / \mathrm{ml}(\mathrm{SD} \pm 3.1 \mathrm{ng} / \mathrm{ml})$. Thirty-three patients were classified as an intermediate-risk group, and 61 patients as the low-risk group. Prostate volume before treatment was assessed using transrectal ultrasonography (TRUS). The average prostate volume before treatment was $35 \mathrm{ml}(\mathrm{SD} \pm 12.3 \mathrm{ml})$. Computed tomography (CT) or magnetic resonance imaging (MRI) were used in individual cases. The patients' characteristics are presented in Table 1. Ethical approval for this retrospective study was sought and obtained from the Ethics Committee of regional University of Medical Sciences. All patients consented to the use of their data for scientific work.

\section{Treatment}

Under general anesthetic, patients receiving LDR-BT were treated with ${ }^{125} \mathrm{I}$ isotope (Eckert \& Ziegler BEBIG ${ }^{\circledR}$ stranded seeds Isocord ${ }^{\circledR}$, Belgium) using ultrasound guidance (BK Medical Pro Focus 2202, UK) and the SPOT planning system (Sonographic Planning of Oncology Treatment - SPOT Pro 3.1, Nucletron, an Elekta company, Elekta AB, Stockholm, Sweden). CT was conducted for dosimetry in 1 day, 1 month, and 3 months after treatment.

Also under general anesthesia, patients in the HDR-BT Group received the prescribed treatment in three separate implants (with breaks of 7-14 days between implants), using HDR ${ }^{192}$ Ir BT afterloader (microSelectron ${ }^{\circledR}$ HDR, Nucletron, an Elekta company, Elekta AB, Stockholm, Sweden), ultrasonographic guidance (BK Medical Pro Focus 2202, UK), and the Oncentra Prostate Planning system version 3.2 (Nucletron, Elekta $\mathrm{AB}$, Stockholm, Sweden).

In both treatment modalities, the clinical target volume was defined included the prostate capsule. According to the consensus of Nucletron Users Meeting, November 2009, Budapest, Hungary, the total dose (TD) for LDR-BT and HDR-BT was changed from 144 to 145 Gy and from 3 fractions of $15 \mathrm{~Gy}$ to 3 fractions of $10.5 \mathrm{~Gy}$, respectively. 
Neoadjuvant or adjuvant ADT was used for volume decrease of large glands (>60 ml). In some cases, the decision of ADT use required a recommendation of urologist. ADT was used in 13 cases from the LDR-BT Group, and in 20 cases from the HDR-BT Group (Table 1).

\section{Evaluation of PSA levels}

All PSA analyses were carried out in the diagnostic laboratory of our hospital. An initial PSA (iPSA) assessment was made in every case prior to treatment. All patients were seen every 3 months for 2 years and subsequently, every 6 months for further 3 years. During each visit, a clinical examination was carried out and PSA assays were performed. BF was defined using the Phoenix definition of PSA nadir $+2 \mathrm{ng} / \mathrm{ml}$. Clinical failure was defined as a rising PSA level and a positive TRUS, MR, $\mathrm{CT}$, or bone scan with X-ray correlation. PSA bounce (PB) was defined as an increase of $>0.2 \mathrm{ng} / \mathrm{ml}$ in PSA level, followed by a spontaneous decrease to the pre-bounce level or lower. The amplitude of the PSA rise was the highest level of PSA classified as PB or BF. The time to the PSA rise was the period of time in months from the last day of treatment to the first day of rising PSA that was classified as PB or BF. Time to nadir was the period of time in months from the last day of treatment to PSA nadir.

\section{Physical factors}

In this study, data was collected from LDR-BT and HDR-BT dose volume histograms. No direct comparison of $\mathrm{D}_{90}$ in $\mathrm{Gy}$ (dose in $90 \%$ of the target volume) was possible, due to radiobiological reasons. The $\mathrm{D}_{90 \mathrm{BED}}$ (biological effective dose) for HDR-BT or LDR-BT was calculated using the following equation: $\mathrm{D}_{90 \mathrm{BED}}=\mathrm{D}_{90}{ }^{*} \mathrm{BED}$.

BED for HDR was calculated using derivation from a linear-quadratic model:

$\mathrm{BED}_{\mathrm{HDR}}=\mathrm{TD}(1+\mathrm{d} / \alpha / \beta)[19]$,

where: TD - total dose, $d$ - fraction dose, $\alpha / \beta-1.5$ Gy [20]. BED for LDR BT was calculated using the following equation:

$\mathrm{BED}_{\mathrm{LDR}}=(\mathrm{R} 0 / \lambda)(1+[\mathrm{R} 0 /(\mu+\lambda)(\alpha / \beta)])[21]$,

where: $R 0$ - initial dose rate of implant $\mathrm{R} 0=\mathrm{D}_{90} * \lambda, \lambda$ - radioactive decay constant $\lambda=0.693 / \mathrm{T}_{1 / 2}, \mu$ - repair rate constant, where $\mu=0.693 / \mathrm{T}_{1 / 2} ; \mathrm{T}_{1 / 2}$ - radioactive half-life of isotope $=60$ days, $\mathrm{T}_{1 / 2}$ - tissue repair half-time $=1$ hour, $\alpha / \beta-$ alpha $/$ beta ratio $=1.5$ Gy [20].

The median $\mathrm{D} 90_{\mathrm{BED}}$ for LDR-BT and HDR-BT was 274 Gy.

\section{Statistics}

Data was collected in a spreadsheet (MS Excel). Statistical analysis was performed using Statistica 8.0 (StatSoft, Inc. Tulsa, USA). The students unpaired $t$-test was applied to determine the significance of differences for continuous variables between the two sample means.
The Mann-Whitney test was used for ordinal and continuous variables without normal distribution. The $\chi^{2}$ test was used for categorical variables. PB free survival was calculated using the Kaplan-Meier method, and comparisons between groups were made using the log-rank test. Univariate Cox regression was used to describe predictive factors for PB. Statistical significance was considered if $p$-value was lower than 0.05 .

\section{Results}

A total of 94 patients were observed in our hospital. In the entire population studied, $24 \%$ of patients experienced PB (Table 1). None of the patients with PB experienced BF during follow-up. The average planning treatment volume (PTV) was $31 \mathrm{ml}$, and was smaller than an average prostate volume prior to treatment in 33 cases. In the follow-up, a median PSA nadir of $0.1 \mathrm{ng} / \mathrm{ml}$ was achieved after a median time of 21 months. In 58 cases, PSA decreased gradually without further event. In 23 cases $(24 \%)$, PB was observed using a definition of $0.2 \mathrm{ng} /$ $\mathrm{ml}$ (Table 1$)$. In 10 cases $(11 \%), \mathrm{BF}$ was diagnosed. There was no significant difference in BF after LDR-BT $(n=6)$ and HDR-BT $(n=4)$ after a median 3 years of follow-up $(p=0.49$, Table 2). Clinical failure (CF) was observed in three patients, out of which, one patient from the LDR-BT intermediate risk group, developed bone metastasis after one year. Two patients from the HDR-BT Group displayed CF. These were patients from the lowrisk group. One of these two patients was subsequently diagnosed with bone metastasis, while in the second, a recurrence was presumed in the prostate owing to findings of positive magnetic resonance and significant elevation of the PSA level. This latter fact was not verified by pathology.

\section{HDR-BT vs. LDR-BT}

The median follow-up time was longer in the LDRBT Group than in the HDR-BT Group (3.1 vs. 2.8 years). LDR-BT patients were younger than HDR patients (64 vs. 67 years, $p<0.016)$. Younger age and longer follow-up time did not increase the PB occurrence in patients after LDR-BT. The occurrence of PB after LDR-BT was similar to that observed in HDR cases $(26 \%$ vs. $22 \%, p=0.49$, Table 2). Clinical stage, Gleason score, iPSA, risk group, and prostate volume were similar in each group. ADT was used with the same frequency in both groups (LDR$\mathrm{BT}=13$ vs. HDR-BT $=20, p=0.697)$. HDR-BT delivered higher $\mathrm{D}_{90 \mathrm{BED}}$ than LDR-BT (345 vs. $178 \mathrm{~Gy}, p<0.001$ ). Higher $\mathrm{D}_{90 \mathrm{BED}}$ after HDR-BT was not associated with lower $\mathrm{BF}, \mathrm{CF}$, or with differences in $\mathrm{PB}$ in the analysis. PSA nadir and time to nadir were also similar in both the LDR-BT and HDR-BT groups (0.2 vs. $0.1 \mathrm{ng} / \mathrm{ml}, p=0.094$, and 24 vs. 18 months, $p=0.166$, respectively). No differences were observed in the occurrence of BF between treatment modalities, but follow-up time was too short to assess the data properly. CF was diagnosed in only three cases and resulted in exclusion of these patients from further analysis for statistical reasons. All data are presented in Table 2. 
Table 2. A comparison of patients after low-dose-rate or high-dose-rate brachytherapy using the Mann-Whitney test

\begin{tabular}{|c|c|c|c|c|c|c|c|c|c|}
\hline \multirow[t]{2}{*}{ Factor } & \multicolumn{4}{|c|}{ LDR-BT } & \multicolumn{4}{|c|}{ HDR-BT } & \multirow[t]{2}{*}{$p$ value } \\
\hline & $N$ & $N(\%)$ & Average $\pm S D$ & Median & $N$ & $N(\%)$ & Average \pm SD & Median & \\
\hline Age [years] & 41 & 100 & $64.0 \pm 7.9$ & 64 & 53 & 100 & $67.8 \pm 7.0$ & 69 & $\underline{0.02^{*}}$ \\
\hline \multicolumn{9}{|l|}{ TNM } & 1 \\
\hline T1c & 22 & 54 & - & - & 30 & 57 & - & - & \\
\hline $\mathrm{T} 2 \mathrm{a}$ & 13 & 32 & - & - & 15 & 28 & - & - & \\
\hline $\mathrm{T} 2 \mathrm{~b}$ & 2 & 5 & - & - & 2 & 4 & - & - & \\
\hline $\mathrm{T} 2 \mathrm{C}$ & 3 & 7 & - & - & 6 & 11 & - & - & \\
\hline n.d. & 1 & 2 & - & - & & & - & - & \\
\hline \multicolumn{9}{|l|}{ Gleason score } & 0.17 \\
\hline$\leq 6$ & 31 & 76 & - & - & 46 & 87 & - & - & \\
\hline 7 & 9 & 22 & - & - & 5 & 9 & - & - & \\
\hline n.d. & 1 & 2 & - & - & 2 & 4 & - & - & \\
\hline iPSA [ng/ml] & 41 & 100 & $8.3 \pm 3.3$ & 8 & 53 & 100 & $7.4 \pm 2.9$ & 7.1 & 0.15 \\
\hline \multicolumn{9}{|l|}{ Risk group } & $0.36^{\star *}$ \\
\hline Low & 24 & 59 & - & - & 37 & 70 & - & - & \\
\hline Intermediate & 17 & 41 & - & - & 16 & 30 & - & - & \\
\hline \multicolumn{9}{|l|}{ ADT } & $0.69^{\star \star}$ \\
\hline Yes & 13 & 32 & - & - & 20 & 38 & - & - & \\
\hline No & 28 & 68 & - & - & 33 & 62 & - & - & \\
\hline Prostate vol $\left[\mathrm{cm}^{3}\right]$ & 41 & 100 & $33.5 \pm 10.6$ & 35 & 53 & 100 & $33.6 \pm 13.5$ & 33 & $0.98^{*}$ \\
\hline Follow-up [years] & 41 & 100 & $3.1 \pm 0.7$ & 3 & 53 & 100 & $2.8 \pm 0.8$ & 2.8 & $\underline{0.04^{*}}$ \\
\hline PTV $\left[\mathrm{cm}^{3}\right]$ & 41 & 100 & $31.8 \pm 10.3$ & 31 & 53 & 100 & $32.6 \pm 11.7$ & 31.4 & $0.73^{\star}$ \\
\hline D90 $0_{\text {BED }}[G y]$ & 41 & 100 & $178.4 \pm 12.5$ & 180 & 53 & 100 & $345.5 \pm 115.9$ & 255.8 & $\leq 0.01$ \\
\hline Nadir PSA [ng/ml] & 41 & 100 & $0.5 \pm 1.1$ & & 53 & 100 & $0.2 \pm 0.4$ & 0.1 & 0.09 \\
\hline Time to nadir [months] & 41 & 100 & $23.7 \pm 14.1$ & 24 & 53 & 100 & $19.5 \pm 14.9$ & 18 & 0.17 \\
\hline \multicolumn{10}{|l|}{ PSA events } \\
\hline No PB & 23 & 56.1 & - & - & 35 & 66.0 & - & - & $0.49^{\star \star *}$ \\
\hline PB & 11 & 26.8 & - & - & 12 & 22.6 & - & - & \\
\hline BF & 6 & 14.6 & - & - & 4 & 7.5 & - & - & \\
\hline CF & 1 & 2.4 & - & - & 2 & 3.8 & - & - & $-^{\star \star \star \star \star}$ \\
\hline
\end{tabular}

$N$ - number of patients, SD - standard deviation, HDR-BT - high-dose-rate brachytherapy, LDR-BT - low-dose-rate brachytherapy, TNM - tumor nodal staging UICC $7^{\text {th }}$ ed. 2010, iPSA - initial prostate antigen level, ADT - androgen deprivation therapy, Vol - volume, PTV - planning tumor volume, $D_{90}$ - dose in $90 \%$ of PTV, $B E D$ - biological effective dose, $P B-P S A$ bounce, $B F-$ biochemical failure, $C F$ - clinical failure

${ }^{*}$ Students unpaired $t$ test, ${ }^{* \star} \chi^{2}$ test, ${ }^{* \star *} \chi^{2}$ test with Yates correction, ${ }^{* * * *}$ excluded form analysis. Significant $p$ values are underlined

The univariate Cox proportional hazards regression demonstrates that variables predictive for PB were only after HDR-BT (Table 3). The use of ADT decreased around 9 times the risk of $\mathrm{PB}$. One Gleason score more reduced almost 2 times the risk of PB after HDR-BT (HR = 0.51, CI: 0.3-0.87, $p=0.01)$. PSA nadir and time to nadir influenced the risk of PB in HDR-BT Group as well. $1 \mathrm{ng} / \mathrm{ml}$ higher PSA nadir increased more than 3 times the risk of $\mathrm{PB}(\mathrm{HR}=3.46, \mathrm{CI}$ : 1.119$10.03, p=0.02)$ and nadir reached 1 month later, increased the risk by around $4 \%(\mathrm{HR}=1.04, \mathrm{CI}: 1.00-1.04, p=0.04$, Table 3$)$. 
Table 3. Cox regression analysis of clinical and pathologic characteristics associated with prostate-specific antigen bounce after low-dose-rate (LDR) or high-dose-rate (HDR) brachytherapy

\begin{tabular}{lcccccc} 
Factor & \multicolumn{3}{c}{ LDR } & \multicolumn{3}{c}{ HDR } \\
\cline { 2 - 8 } & $95 \% \mathrm{Cl}$ & HR & $p$ value & $95 \% \mathrm{Cl}$ & HR & $p$ value \\
\hline Tumour stage & $0.54-1.54$ & 0.92 & 0.74 & $0.58-1.37$ & 0.9 & 0.63 \\
\hline Gleason score & $0.53-1.19$ & 0.79 & 0.25 & $0.3-0.87$ & 0.51 & 0.01 \\
\hline \multicolumn{1}{c}{ iPSA } & $0.84-1.27$ & 1.03 & 0.75 & $0.96-1.35$ & 1.14 & 0.13 \\
\hline Risk group & $0.08-1.74$ & 0.38 & 0.21 & $0.21-2.91$ & 0.79 & 0.72 \\
\hline ADT & $0.13-1.81$ & 0.48 & 0.28 & $0.1-0.85$ & 0.11 & 0.03 \\
\hline Prostate volume $\left(\mathrm{cm}^{3}\right)$ & $0.99-1.00$ & 1 & 0.76 & $0.93-1.02$ & 0.97 & 0.28 \\
\hline D90 (BED) & $0.93-1.02$ & 0.98 & 0.27 & $0.99-1.00$ & 1 & 0.89 \\
\hline Nadir PSA (ng/ml) & $0.83-11.90$ & 3.14 & 0.09 & $1.19-10.03$ & 3.46 & 0.02 \\
\hline Time to nadir (months) & $0.97-1.06$ & 1.01 & 0.49 & $1.00-1.08$ & 1.04 & 0.04
\end{tabular}

$H D R$ - high-dose-rate, LDR - low-dose-rate, iPSA - initial prostate specific antigen, ADT-androgen deprivation therapy, $D_{90}-$ dose in $90 \%$ of PTV, BED - biological effective dose, $\mathrm{Cl}$-confidence interval, $\mathrm{HR}$ - hazard ratio

Table 4. Comparison of patients with prostate-specific antigen bounce in low-dose-rate and high-dose-rate brachytherapy groups using the Mann-Whitney test

\begin{tabular}{|c|c|c|c|c|c|c|c|c|c|}
\hline \multirow[t]{2}{*}{ Factor } & \multicolumn{4}{|c|}{ LDR-BT PSA bounce } & \multicolumn{4}{|c|}{ HDR-BT PSA bounce } & \multirow[t]{2}{*}{$p$ value } \\
\hline & $N$ & $N(\%)$ & Average \pm SD & Median & $N$ & $N(\%)$ & Average \pm SD & Median & \\
\hline Age [years] & 11 & 100 & $62.2 \pm 4.9$ & 62 & 12 & 100 & $65.7 \pm 6.7$ & 66.5 & $0.16^{\star}$ \\
\hline TNM & & & & & & & & & 0.79 \\
\hline T1c & 7 & 63.6 & - & - & 9 & 75.0 & - & - & \\
\hline T2a & 3 & 27.3 & - & - & 1 & 8.3 & - & - & \\
\hline $\mathrm{T} 2 \mathrm{~b}$ & 1 & 9.1 & - & - & - & - & - & - & \\
\hline $\mathrm{T} 2 \mathrm{c}$ & - & & - & - & 2 & 16.7 & - & - & \\
\hline Gleason score & & & & & & & & & 0.34 \\
\hline$\leq 6$ & 10 & 90.9 & - & - & 12 & 100 & - & - & \\
\hline 7 & 1 & 9.1 & - & - & - & - & - & - & \\
\hline iPSA [ng/ml] & 11 & 100 & $7.9 \pm 3.4$ & 7.7 & 12 & 100 & $8.5 \pm 3.7$ & 7.9 & 0.62 \\
\hline Risk group & & & & & & & & & $0.91^{\star \star}$ \\
\hline Low & 9 & 81.8 & - & - & 9 & 75.0 & - & - & \\
\hline Intermediate & 2 & 18.2 & - & - & 3 & 25.0 & - & - & \\
\hline ADT & & & & & & & & & $0.93^{* *}$ \\
\hline Yes & 9 & 81.8 & - & - & 11 & 91.7 & - & - & \\
\hline No & 2 & 18.2 & - & - & 1 & 8.3 & - & - & \\
\hline Prostate vol $\left[\mathrm{cm}^{3}\right]$ & 11 & 100 & $37.3 \pm 9.5$ & 38 & 12 & 100 & $28.9 \pm 12.1$ & 28 & $0.08^{\star}$ \\
\hline PTV $\left[\mathrm{cm}^{3}\right]$ & 11 & 100 & $30.8 \pm 7.3$ & 30.2 & 12 & 100 & $31.1 \pm 9.5$ & 28.9 & $0.94^{*}$ \\
\hline D90 ${ }_{B E D}[G y]$ & 11 & 100 & $170.4 \pm 24.9$ & 175.7 & 12 & 100 & $346.2 \pm 124$ & 254.9 & $\leq 0.01$ \\
\hline Follow-up [years] & 11 & 100 & $3.2 \pm 0.6$ & 3.1 & 12 & 100 & $3.1 \pm 0.9$ & 2.9 & 0.23 \\
\hline Nadir PSA [ng/ml] & 11 & 100 & $0.4 \pm 0.4$ & 0.4 & 12 & 100 & $0.4 \pm 0.4$ & 0.3 & 0.54 \\
\hline Time to nadir [months] & 11 & 100 & $26.1 \pm 13.9$ & 30 & 12 & 100 & $28.5 \pm 13$ & 33 & $0.69^{*}$ \\
\hline $\begin{array}{l}\text { Amplitude of PSA chang- } \\
\text { es[ng/ml] }\end{array}$ & 11 & 100 & $0.7 \pm 1.1$ & 0.4 & 12 & 100 & $0.8 \pm 0.5$ & 0.7 & 0.14 \\
\hline Time to PSA rise & 11 & 100 & $18.9 \pm 6.4$ & 18 & 12 & 100 & $10.7 \pm 4.8$ & 10.5 & $\leq 0.01^{*}$ \\
\hline
\end{tabular}

$N$ - number of patients, SD - standard deviation, HDR-BT - high-dose-rate brachytherapy, LDR-BT - low-dose-rate brachytherapy, TNM - tumor nodal staging UICC $7^{\text {th }}$ ed. 2010, iPSA - initial prostate antigen level, ADT-androgen deprivation therapy, Vol - volume, PTV - planning target volume, $D_{90}-$ dose in $90 \%$ of PTV, $B E D$ - biological effective dose

${ }^{*}$ Students unpaired $t$ test, ${ }^{* *} \chi^{2}$ test. Significant $p$ values are underlined 


\section{PSA bounce after LDR-BT or HDR-BT}

There was no difference in age between PB patients of the LDR-BT and HDR-BT Group. The patients had average ages of 62 and 66 years, respectively, $p=0.165$ (Table 4). Clinical stage, Gleason score, and risk group were all found to be statistically insignificant in PB patients. ADT was also used with similar frequency in patients with PB ( 81.8 vs. $91.7 \%, p=0.935)$. The volume of prostate and PTV for treatment were similar in both groups (average $37 \mathrm{~cm}^{3}$ and $30.8 \mathrm{~cm}^{3}$ for LDR-BT, and 29 $\mathrm{cm}^{3}$ and $31 \mathrm{~cm}^{3}$ for HDR-BT, respectively). HDR-BT delivered higher mean $\mathrm{D}_{90 \mathrm{BED}}(346 \mathrm{~Gy}$ ) than was observed in LDR-BT (170 Gy), $p<0.01$. Higher $\mathrm{D}_{90 \mathrm{BED}}$ after HDRBT did not influence PB rate, and was not associated with a lower BF rate in the analysis. The PSA nadir and time to nadir were similar in both HDR-BT and LDR-BT Groups, (median 0.3 vs. $0.4 \mathrm{ng} / \mathrm{ml}, p=0.538$, average 26 vs. 28 months, $p=0.691$, respectively).

Time to PSA rise before PB was significantly different between both groups. After HDR-BT, PSA levels increased after an average of 10.5 months; an increase in the LDR-BT Group was observed after 18 months, $p=0.003$ (Table 2, Figure 1). The difference made a trend in freedom from $\mathrm{PB}$ assessed with the Kaplan Meier method and the log-rank test ( $p=0.07$, Figure 2). The amplitude of PSA rises was similar in both groups $(0.8 \mathrm{vs} .0 .7 \mathrm{ng} / \mathrm{ml})$. No patients with $\mathrm{PB}$ experienced $\mathrm{BF}$ or clinical failure. All data are presented in Table 4.

\section{Discussion}

PB was first described over twenty years ago, and is still a challenge for both physicians and patients. PB after BT has been widely described in patients after LDR-BT $[7,12,22]$. To date, only few studies have been published regarding PB after HDR-BT as a monotherapy. The number of patients after HDR-BT is rising, and both physicians and patients, must be aware of the different PSA kinetics, in comparison to LDR-BT. In this study, we aimed to highlight the main differences between PSA kinetics after LDRBT or HDR-BT, and to describe the predictive factors for PB in order to reduce the likelihood of unnecessary treatment.

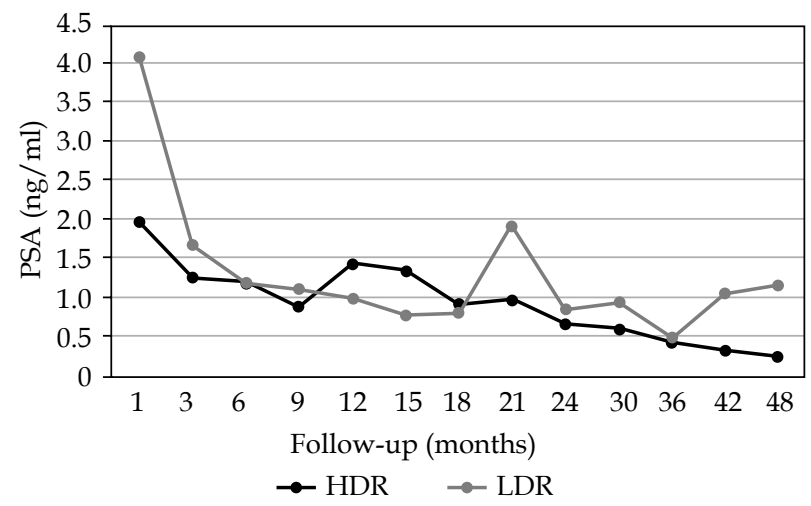

Fig. 1. The graph presents the average prostate-specific antigen (PSA) level in patients with prostate-specific antigen bounce after low-dose-rate (LDR) or high-dose-rate (HDR) brachytherapy
In general, PB after LDR-BT is diagnosed in $28-49 \%$ of cases using a well-established $0.2 \mathrm{ng} / \mathrm{ml}$ definition $[7,8,11,13,14]$. In around $10 \%$ of cases, PB exceeds the $2 \mathrm{ng} / \mathrm{ml}$ limit [11]. In our study, PB was diagnosed in $24.5 \%$, and the frequency of $\mathrm{PB}$ was similar in groups after LDR-BT $(27 \%)$ and after HDR-BT $(23 \%)$. In the report of Mehta et al., PB rate after HDR-BT $(n=157)$ alone was significantly higher (43\%) than in our study [16]. McGrath et al. observed PB frequency after EBRT + HDR-BT boost $(n=407)$, LDR-BT $(n=191)$, and HDR-BT $(n=91)$, and found that the PB rate after HDR-BT alone was $46 \%$ in their analysis of patients with and without ADT [15]. In this study, PB rate was significantly higher after HDRBT than after others modalities: using a PB definition of $0.3 \mathrm{ng} / \mathrm{ml}$, the results were HDR-BT $=40 \%$, HDR-BT boost $=29 \%$, and LDR-BT $=25 \%(p=0.04)$ or, when using a definition of $0.5 \mathrm{ng} / \mathrm{ml}$, the results were HDR-BT $=29 \%$, HDR-BT boost $=18 \%$, and LDR-BT $=16 \%(p=0.02)$. Other analyzed definitions from $0.1 \mathrm{ng} / \mathrm{ml}$ to $4.0 \mathrm{ng} / \mathrm{ml}$ were not found to be significant. The PB rate in our study was lower than those reported in the literature, even when the same definition was used, although median follow-up in our study was only 3 years. The median follow-up periods in the studies of Mehta et al. and McGrath et al. were 4.6 and 4.0 years, respectively $[15,16]$.

Age was one of the first and most frequently described predictive factors for PB. Many studies, looking at patients aged between 60 and 70 years of age, have shown that younger patients have a higher probability of PB $[7,8,23,24,25,26]$. However, some studies observed no influence of age on the occurrence of $\mathrm{PB}$ rate after LDR-BT [27]. Only few studies were published describing the frequency of PB after HDR-BT. Mehta et al. had defined the age $<55$ years as being a predisposing factor for $\mathrm{PB}$ in univariate and multivariate analyses $(\mathrm{OR}=2.02$, $p<0.01$, and $\mathrm{OR}=2.22, p<0.01$, respectively) [16].

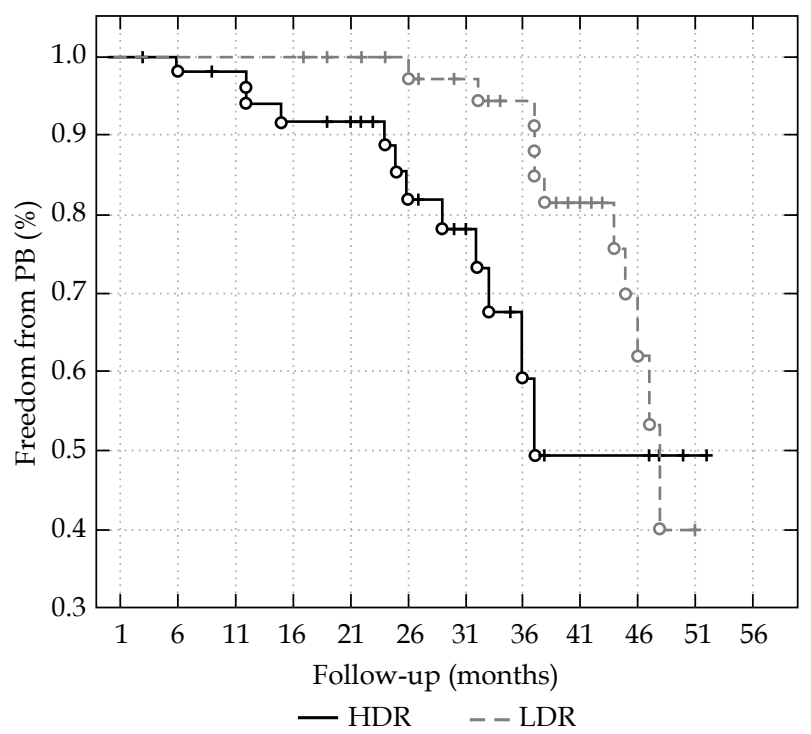

Fig. 2. The Kaplan-Meier curves of freedom from prostate-specific antigen bounce (PB) in low-dose-rate (LDR) or high-dose-rate (HDR) brachytherapy group and theirs comparison using log rank test $(p=0.07)$. 
McGrath et al. did not assess the age as a predictive factor [15]. It was hypothesized that the etiology of PB could be explained with younger age. Younger patients had higher androgen level and more active glandular cells, and were more often sexual active what increases PSA level. However, older patients had bigger glandular zone, what suggests different effect on higher PSA level. On the other hand, in work of Crook et al., the age was a factor for PB and the potency was a predictive factor for $\mathrm{PB}$ in univariate analysis [7].

In our study, the LDR-BT Group was younger than the HDR-BT Group (64 vs. 67.8 years, $p=0.016$, Table 2 ), though no increase in the PB rate was observed in the LDR-BT Group. Regardless of treatment modality, no age related difference was observed in patients with PB. Possibly, the effects of age would be more obvious in a larger study population.

ADT decreases the testosterone and PSA levels. The recovery of testosterone as a consequence of the termination of ADT influences PSA kinetics. Pickels et al. reported in their analysis of 2,030 men treated for prostate cancer with EBRT $(n=1581)$ and LDR-BT $(n=449)$ with or without ADT, that PB after LDR-BT was more common in the ADT group ( $89 \%$ vs. $71 \%)$. In their study, any rise in PSA level that was followed by a fall of any magnitude was defined as PB. Moreover, Pickels in the subsequent analysis of this group, observed that ADT prolonged the duration of $\mathrm{PB}$ (6.7 vs. 12.5 month) [28]. McGrath et al. (HDR-BT alone, $n=93$ ) also reported prolonged PB in the ADT group, using a definition of 0.1 to $1.0 \mathrm{ng} / \mathrm{ml}$. The PB rate was increased in the ADT group using a definition of absolute nadir (the lowest PSA in whole follow-up time), but that difference was not seen when using a definition of current nadir (the lowest level recorded prior to the current measurements). However, PB in whole group was more often observed using the current nadir definition [15].

The current nadir definition was used in the studies of Ciezki et al. They analyzed patients after LDR-BT, and did not observe any increase in the probability of $\mathrm{PB}$ after ADT ( $45 \%$ ADT vs. $48.4 \%$ hormone naive, $p=0.67$ ) [18]. In the study of Toledano et al., ADT had no influence on either PB rate or on its magnitude [25]. In the study of Mehta et al., ADT was not associated with an increased rate of PB in patients after HDR-BT, in neither univariate or multivariate analyses [16]. In our analysis, the ADT rate in patients with PB was the same in both LDR-BT and HDR-BT Groups (81.8 vs. $91.7 \%, p=0.935$, Table 4), but only after HDR-BT it reduced 9 times the risk of the PB (Table 3). In patients after ADT, PSA level falls down and slowly raises up to stable low level without PB. ADT naive patients after HDR-BT had higher PSA, could more easy fulfil the $0.2 \mathrm{ng} / \mathrm{ml}$ rise definition. Patients after LDR who had ADT were still irradiated, what could influence the prostate tissue and cause the PB more frequent.

Time to the occurrence of $\mathrm{PB}$ may help to distinguish it from BF. It has been reported that PB usually occurs between 13 to 30 months after LDR-BT $[17,26]$. Hackett et al., using a nadir definition of $+2 \mathrm{ng} / \mathrm{ml}$, observed $100 \%$ PB during the first 3 years after LDR BT in 530 patients, and only time to PSA rise independently differentiated between bounce and failure $(p<0.01)$ [29]. It has also been stated by Thompson et al. that PB is not observed after 5 years of follow-up, even when using ADT and the $2 \mathrm{ng} /$ $\mathrm{ml}$ definition [30]. According to McGrath et al., the median time to PB was 15 months [15]. Similarly, Mehta et al. observed PB after a median period of 1.3 years [16]. In our analysis, the time to $\mathrm{PB}$ was 10.5 months following HDR-BT, and 18 months following LDR-BT $(p<0.01$, Table 4). The shorter period leading to PB occurrence might be explained by the shorter treatment time in the HDR-BT Group. LDR-BT treatment can last for as much as 10 half-lives of the isotope, which is almost 2 years for ${ }^{125}$ I seeds [21]. The later occurrence of PB in the LDR-BT Group appears to be connected with treatment time in our study. PB seems to reflect the effects of radiotherapy on the late responding tissues. Late effects occur earlier and are more pronounced with higher doses and shorter treatment times (as is the case with HDR-BT). PB after HDR-BT was observed earlier in our study than in that of Mehta et al. (10.5 vs. 15.6 months [1.3 years], respectively) [16]. We used a higher dose per fraction and a different schedule, compared to that of the University of California ( $3 \times 10.5$ to $15 \mathrm{~Gy}, 3$ implant procedures within $3-4$ weeks vs. $6 \times 7$ Gy, 2 implant procedures within 1 week).

Time to PSA nadir and nadir PSA were significant predictors of PSA bounce after HDR-BT in our study. However, they were not significant predictors after LDRBT. In the study by Merrick et al., PSA nadir was significant predictor for PB after LDR-BT [24]. The investigators observed that when stratified into 3 different groups of PSA nadir, patients with PSA nadir $\geq 1.0-0.5 \mathrm{ng} / \mathrm{ml}$ were more likely to have PB $(80 \%)$ than those with PSA nadir of $0.5-0.2 \mathrm{ng} / \mathrm{ml}(50 \%)$ and $<0.2 \mathrm{ng} / \mathrm{ml}(20 \%$, $p<0.001$ ) [24]. On the other hand, in study reported by Aaltomaa et al. from Finland, the PB was more commonly seen in group patients (LDR-BT, $n=444$ ) with PSA nadir $<0.5 \mathrm{ng} / \mathrm{ml}$ than with the higher PSA nadir [31]. In our study, in patients after HDR-BT, $1 \mathrm{ng} / \mathrm{ml}$ higher PSA nadir would increase the risk of $\mathrm{PB}$ almost 3 and half times (HR 3.46, $p=0.02$, Table 3), and nadir achieved 1 month later increased the risk of PB in $4 \%$ per month.

Gleason score has not been observed as a predictor PB after LDR-BT [11]. However, in the study of Mehta et al. with patients after HDR-BT, lower Gleason score was a predictor of $\mathrm{PB}$ in multivariable analysis $(\mathrm{OR}=0.66$, $p=0.045$ ) [16]. In our study, we similarly noted, that Gleason score had no impact on PB after LDR-BT, but lower Gleason score in patients after HDR-BT was associated with higher risk of PB (Table 3). The explanation of Gleason score influence seems to be unclear and need further investigations.

The impact of other physical factors was also investigated in terms of PB. Almost all published studies have been performed using ${ }^{125} \mathrm{I}$ permanent implantation. Merrick et al., who analyzed 218 patients after LDR-BT with ${ }^{125} \mathrm{I}(n=69)$ or ${ }^{103} \mathrm{Pd}(n=29)$ and EBRT + LDR-BT $(n=120)$, observed that ${ }^{125} \mathrm{I}$ caused more instances of PB than ${ }^{103} \mathrm{Pd}$ [24]. This finding was confirmed in a randomized trial conducted by the group and reported by Bostancic et al. It was observed that hormone-naive ${ }^{125}$ I patients 
were more than three times as likely as hormone-naive ${ }^{103} \mathrm{Pd}$ patients to develop PB (45.7\% vs. $\left.14.0 \%\right)$ [32]. ${ }^{103} \mathrm{Pd}$ has a higher dose rate than ${ }^{125} \mathrm{I}$, but this tendency to higher dose rates and lower PB rates was not observed in a comparison of HDR-BT and LDR-BT. However, in the work of McGrath, higher PB rates after HDR-BT using 0.3 and $0.5 \mathrm{ng} / \mathrm{ml}$ definitions was observed [15]. In our study, neither the dose rate nor the choice of isotopes (LDR-BT vs. HDR-BT) had any influence on PB rate when using the $0.2 \mathrm{ng} / \mathrm{ml}$ definition. TD and intra-operative dosimetric factors have also been studied. Toledano et al. reported that $\mathrm{D}_{90}>200 \mathrm{~Gy}$ was a predictive for PB [25]. Stock et al. stated that $\mathrm{D}_{90}>160 \mathrm{~Gy}$ was predictive for PB [26]. However, Merrick et al. observed that $\mathrm{D}_{90}<115 \%$ or $\mathrm{V}_{150}<55 \%$ were strongly predictive for $\mathrm{PB}$ occurrence [24]. In our study, the $\mathrm{D}_{90 \mathrm{BED}}$ varied between the HDR-BT and LDR-BT Groups, but did not influence the frequency of PB.

The clinical significance of $\mathrm{PB}$ remains controversial after BT. It is known that PB correlates with BF after EBRT. Horwitz et al. showed that PB after EBRT correlated with $\mathrm{BF}$ in $20 \%$ of cases $(n=4,838$, definition $0.4 \mathrm{ng} / \mathrm{ml})$ [33].

Conversely, in their study of 975 cases, Hinnen et al. found that $\mathrm{PB}(32 \%)$ after LDR-BT is a predictive factor for better outcome. In the PB group, overall survival, disease free survival, and biochemical free survival after 10 years were $88 \%, 99 \%$, and $90 \%$, respectively, whilst the same results for the non PB group were $82 \%, 93 \%$ and $70 \%$, respectively [12]. A meta-analysis published by Bernstein et al. included 3,011 patients from over 6 studies treated with prostate LDR-BT. It revealed that a decreased risk of $\mathrm{BF}$ (HR $=0.42,95 \%$ CI: 0.3-0.59, $p<0.001)$ was conferred on patients with PB [22]. On the other hand, in group of McGrath et al. was observed that $\mathrm{PB}>0.4 \mathrm{ng} / \mathrm{ml}$ resulted in a greater probability of $\mathrm{BF}$ using the $+2 \mathrm{ng} / \mathrm{ml}$ definition of nadir (12 vs. 20, $p=0.01$ ). In this study, PB $<0.3 \mathrm{ng} /$ $\mathrm{ml}$ had no effect on BF. However, patients from the group that were treated with BT alone, either LDR-BT or HDRBT, accounted for only $41 \%$ of cases [15]. In our study, no patients with PB experienced BF. However, our study had access to only a short follow-up period of this small group of patients for the proper assessment of $\mathrm{BF}$.

\section{Conclusions}

In our experience, HDR-BT and LDR-BT for low- and intermediate-risk prostate cancer had the same $\mathrm{PB}$ rate (average, 24\%) using a definition of $0.2 \mathrm{ng} / \mathrm{ml}$. The PB occurred earlier after HDR-BT than after LDR-BT. HDRBT delivered a higher $\mathrm{D} 90_{\mathrm{BED}}$, but did not influence the $\mathrm{PB}$ rate. ADT and higher Gleason score decreased the risk of PB, and the higher PSA nadir and longer time to PSA nadir increased the risk of PB after HDR-BT. Predictors for PB were not observed after LDR-BT.

\section{Disclosure}

Autors report no conflict of interest.

\section{References}

1. Chin J, Rumble RB, Kollmeier M et al. Brachytherapy for Patients with Prostate Cancer: American Society of Clinical On-
cology/Cancer Care Ontario Joint Guideline Update. J Clin Oncol 2017; 35: 1737-1743.

2. Davis BJ, Horwitz EM, Lee WR et al. American Brachytherapy Society consensus guidelines for transrectal ultrasoundguided permanent prostate brachytherapy. Brachytherapy 2012; 11: 6-19.

3. Kovacs G, Potter R, Loch T et al. GEC/ESTRO-EAU recommendations on temporary brachytherapy using stepping sources for localised prostate cancer. Radiother Oncol 2005; 74: 137-148.

4. Skowronek J. Low-dose-rate or high-dose-rate brachytherapy in treatment of prostate cancer - between options. J Contemp Brachytherapy 2013; 5: 33-41.

5. Yamada Y, Rogers L, Demanes DJ et al. American Brachytherapy Society consensus guidelines for high-dose-rate prostate brachytherapy. Brachytherapy 2012; 11: 20-32.

6. Roach $M 3^{\text {rd }}$, Hanks G, Thames H, Jr. et al. Defining biochemical failure following radiotherapy with or without hormonal therapy in men with clinically localized prostate cancer: recommendations of the RTOG-ASTRO Phoenix Consensus Conference. Int J Radiat Oncol Biol Phys 2006; 65: 965-974.

7. Crook J, Gillan C, Yeung I et al. PSA kinetics and PSA bounce following permanent seed prostate brachytherapy. Int J Radiat Oncol Biol Phys 2007; 69: 426-433.

8. Patel C, Elshaikh MA, Angermeier K et al. PSA bounce predicts early success in patients with permanent iodine-125 prostate implant. Urology 2004; 63: 110-113.

9. Wallner KE, Blasko J, Dattoli MJ. Evaluating cancer status. Prostate brachytherapy made complicated. Smart Medicine Press; Seattle 1997.

10. Crouzet S, Rebillard X, Chevallier D et al. Multicentric oncologic outcomes of high-intensity focused ultrasound for localized prostate cancer in 803 patients. Eur Urol 2010; 58: 559-566.

11. Caloglu M, Ciezki J. Prostate-specific antigen bounce after prostate brachytherapy: review of a confusing phenomenon. Urology 2009; 74: 1183-1190.

12. Hinnen KA, Monninkhof EM, Battermann JJ et al. Prostate specific antigen bounce is related to overall survival in prostate brachytherapy. Int J Radiat Oncol Biol Phys 2012; 82: 883-888.

13. Mazeron R, Bajard A, Montbarbon X et al. Permanent 125I-seed prostate brachytherapy: early prostate specific antigen value as a predictor of PSA bounce occurrence. Radiat Oncol 2012; 7:46.

14. Zwahlen DR, Smith R, Andrianopoulos N et al. Prostate-specific antigen bounce after permanent iodine-125 prostate brachytherapy - an Australian analysis. Int J Radiat Oncol Biol Phys 2011; 79: 179-187.

15. McGrath SD, Antonucci JV, Fitch DL et al. PSA bounce after prostate brachytherapy with or without neoadjuvant androgen deprivation. Brachytherapy 2010; 9: 137-144.

16. Mehta NH, Kamrava M, Wang PC et al. Prostate-specific antigen bounce after high-dose-rate monotherapy for prostate cancer. Int J Radiat Oncol Biol Phys 2013; 86: 729-733.

17. Merrick GS, Butler WM, Wallner KE et al. Prostate-specific antigen (PSA) velocity and benign prostate hypertrophy predict for PSA spikes following prostate brachytherapy. Brachytherapy 2003; 2: 181-188.

18. Ciezki JP, Reddy CA, Garcia J et al. PSA kinetics after prostate brachytherapy: PSA bounce phenomenon and its implications for PSA doubling time. Int J Radiat Oncol Biol Phys 2006; 64: 512-517.

19. Joiner M, Van der Kogel A. Basic Clinical Radiobiology. $4^{\text {th }}$ ed. Hodder Education, 2009.

20. Brenner DJ, Martinez AA, Edmundson GK et al. Direct evidence that prostate tumors show high sensitivity to fractionation (low alpha/beta ratio), similar to late-responding normal tissue. Int J Radiat Oncol Biol Phys 2002; 52: 6-13. 
21. Dale RG. Radiobiological assessment of permanent implants using tumour repopulation factors in the linear-quadratic model. Br J Radiol 1989; 62: 241-244.

22. Bernstein MB, Ohri N, Hodge JW et al. Prostate-specific antigen bounce predicts for a favorable prognosis following brachytherapy: a meta-analysis. J Contemp Brachytherapy 2013; 5: 210-214.

23. Critz FA, Williams WH, Levinson AK et al. Prostate specific antigen bounce after simultaneous irradiation for prostate cancer: the relationship to patient age. J Urol 2003; 170: 18641867.

24. Merrick GS, Butler WM, Wallner KE et al. Prostate-specific antigen spikes after permanent prostate brachytherapy. Int J Radiat Oncol Biol Phys 2002; 54: 450-456.

25. Toledano A, Chauveinc L, Flam T et al. PSA bounce after permanent implant prostate brachytherapy may mimic a biochemical failure: a study of 295 patients with a minimum 3-year follow up. Brachytherapy 2006; 5: 122-126.

26. Stock RG, Stone NN, Cesaretti JA. Prostate-specific antigen bounce after prostate seed implantation for localized prostate cancer: descriptions and implications. Int J Radiat Oncol Biol Phys 2003; 56: 448-453.

27. Das $\mathrm{P}$, Chen $\mathrm{MH}$, Valentine $\mathrm{K}$ et al. Using the magnitude of PSA bounce after MRI-guided prostate brachytherapy to distinguish recurrence, benign precipitating factors, and idiopathic bounce. Int I Radiat Oncol Biol Phys 2002; 54: 698-702.

28. Pickles T. Prostate-specific antigen (PSA) bounce and other fluctuations: which biochemical relapse definition is least prone to PSA false calls? An analysis of 2,030 men treated for prostate cancer with external beam or brachytherapy with or without adjuvant androgen deprivation therapy. Int J Radiat Oncol Biol Phys 2006; 64: 1355-1359.

29. Hackett C, Ghosh S, Sloboda R et al. Distinguishing prostatespecific antigen bounces from biochemical failure after lowdose-rate prostate brachytherapy. J Contemp Brachytherapy 2014; 6: 247-253

30. Thompson A, Keyes M, Pickles T et al. Evaluating the Phoenix definition of biochemical failure after (125) I prostate brachytherapy: Can PSA kinetics distinguish PSA failures from PSA bounces? Int J Radiat Oncol Biol Phys 2010; 78: 415-421.

31. Aaltomaa SH, Kataja VV, Lahtinen T et al. Eight years' experience of local prostate cancer treatment with permanen I125 seed brachytherapy - morbidity and outcome results. Radiother Oncol 2009; 91: 213-216.

32. Bostancic C, Merrick GS, Butler WM et al. Isotope and patient age predict for PSA spikes after permanent prostate brachytherapy. Int J Radiat Oncol Biol Phys 2007; 68: 1431-1437.

33. Horwitz EM, Levy LB, Thames HD et al. Biochemical and clinical significance of the posttreatment prostate-specific antigen bounce for prostate cancer patients treated with external beam radiation therapy alone: a multi-institutional pooled analysis. Cancer 2006; 107: 1496-1502. 